\title{
O USO DE NOTÍCIAS ON LINE E DE TELEJORNAIS PARA MEDIAR OS CONTEÚDOS DE CLIMATOLOGIA NAS AULAS DE GEOGRAFIA
}

The use of online news and television news to mediate climatology contents in geography classes

El uso de noticias en línea y de tv para mediar los contenidos de climatología en las clases de geografía

\author{
Hemerson Souza Gomes ${ }^{*}$ \\ Ana Claudia Ramos Sacramento*
}

\begin{abstract}
Universidade do Estado do Rio de Janeiro (UERJ/FFP) - Hemerson89@hotmail.com. Universidade do Estado do Rio de Janeiro (UERJ/FFP) - Anaclaudia.sacramento@hotmail.com
\end{abstract}

Recebido em 20/10/2019. Aceito para publicação em 20/10/2019.

Versão online publicada em 10/11/2019 (http://seer.ufrgs.br/paraonde)

Resumo:

Os fenômenos climáticos acontecem na vida cotidiana de todos e trazem diferentes impactos econômicos, sociais, culturais e físicos; de acordo com a escala de análise. Seu estudo se torna pertinente e relevante, em sala de aula, para que os estudantes compreendam seus conceitos e conteúdos e, com isso, possam realizar análises de diferentes impactos no espaço geográfico. Assim, este trabalho objetiva observar e discorrer sobre a importância do estudo de clima como forma de mediação do conhecimento geográfico em sala de aula. Como metodologia, a partir da pesquisa-ação, foram desenvolvidas atividades didáticas com o uso de notícias de jornais online e telejornais, para que os estudantes do primeiro ano do ensino médio potencializassem a leitura espacial a partir desses recursos didáticos. Desta forma, acredita-se que a interpretação e análise dos fenômenos pelos alunos serão aprimoradas. Portanto, pode-se concluir que uma mediação mais significativa sobre o ensino da climatologia geográfica e a aproximação dos estudantes aos conteúdos resultaram não somente em uma participação mais ativa do processo de ensino, como também em um aperfeiçoamento da aprendizagem.

Palavras-chave: Notícias. Conteúdos de Climatologia. Ensino de Geografia.

\section{Abstract:}

Climatic phenomena happen in everyone's daily life and bring different economic, social, cultural and physical impacts; according to the analysis scale. Their study becomes pertinent and relevant in the classroom, so that students understand their concepts and contents and, so, can perform analyzes of different impacts on the geographical space. Thus, this paper aims to observe and discuss the importance of climate study as a way of mediating geographic knowledge in the classroom. As methodology, from the action research, didactic activities were developed with the use of news from online newspapers and news programs, so that the students of the first year of high school could enhance the spatial reading from these didactic resources. So, it is believed that the interpretation and analysis of the phenomena by students will be improved. Therefore, it can be concluded that a more significant mediation about the teaching of geographical climatology and the students' approach to the contents resulted not only in a more active participation of the teaching process, but also in an improvement of the learning.

Keywords: News. Climatology contents. Geography teaching. 


\section{Resumen:}

Los fenómenos climáticos ocurren en la vida diaria de todos y traen diferentes impactos económicos, sociales, culturales y físicos; según la escala de análisis Su estudio se vuelve relevante y relevante en el aula, para que los estudiantes entiendan sus conceptos y contenidos y, por lo tanto, puedan realizar análisis de diferentes impactos en el espacio geográfico. Por lo tanto, este documento tiene como objetivo observar y discutir la importancia del estudio del clima como una forma de mediar el conocimiento geográfico en el aula. Como metodología, a partir de la investigación de acción, se desarrollaron actividades didácticas con el uso de noticias de periódicos en línea y programas de noticias, para que los estudiantes del primer año de secundaria pudieran mejorar la lectura espacial de estos recursos didácticos. Por lo tanto, se cree que se mejorará la interpretación y el análisis de los fenómenos por parte de los estudiantes. Por lo tanto, se puede concluir que una mediación más significativa sobre la enseñanza de la climatología geográfica y el enfoque de los estudiantes sobre los contenidos resultó no solo en una participación más activa del proceso de enseñanza, sino también en una mejora del aprendizaje.

Palabras clave: Noticias. Contenidos de climatología. Enseñanza de geografía.

\section{Introdução}

A relevância do ensino de Geografia não se faz apenas no ambiente escolar, mas, principalmente, para a formação de um indivíduo consciente de seu espaço de vivência. $A$ partir do conhecimento geográfico, o indivíduo vai não somente conhecer o espaço onde está inserido, como também vai entender suas transformações físicas e sociais, podendo discernir onde essas transformações têm interferências humanas ou naturais.

No processo de ensino-aprendizagem, faz-se necessário entender que há uma troca de saberes entre sujeitos e cada um traz consigo conhecimentos em contextos próprios. Por isso, tais saberes empíricos devem ser considerados nesse processo. Nesse sentido, o cotidiano se torna essencial para a análise do espaço geográfico, trabalhado o espaço vivido pelos discentes e docentes para a adesão de uma aprendizagem mais significativa (STEINKE; FIALHO, 2017, p. 77).

É importante lembrar que apesar de se trabalhar com o visível, alguns conteúdos carregam grande abstração como, por exemplo, as áreas e os temas trabalhados em sala de aula (climatologia, geomorfologia, tectônica de placas, entre outros). Ao ensinar geografia, é necessário o uso de diferentes métodos e estratégias de aprendizagem, para que se tenha uma mediação mais eficiente desses temas mais abstratos.

O clima é influente no meio natural e social, uma vez que interage tanto com elementos naturais como sociais, e entendê-lo é de suma importância para uma formação completa e efetiva dos estudantes, para que construam, de forma crítica, uma consciência acerca do espaço onde vivem. Assim, o estudo do clima urbano justifica-se, pois possibilita a compreensão do espaço geográfico. Por isso, esse entendimento precisa acontecer a partir de uma leitura espacial que integre sociedade e natureza, unindo-os e não fragmentando tais áreas.

O surgimento da climatologia como um campo do conhecimento científico com identidade própria deu-se algum tempo depois da sistematização da meteorologia. Voltada ao estudo da espacialização dos elementos e fenômenos atmosféricos e de sua evolução, a climatologia integra-se como uma subdivisão da Meteorologia e da Geografia. Esta compõe o campo das ciências humanas e estuda o espaço geográfico a partir da interação da sociedade com a natureza. (MENDONÇA; DANNI-OLIVEIRA, 2007, p. 14)

ParaOnde!?, Porto Alegre, v.12 n.2, p.146-154, 2019. http://seer.ufrgs.br/paraonde Edição Especial - III Colóquio de Pesquisadores em Geografia Física Ensino de Geografia 
A climatologia diferencia-se da meteorologia não somente por tratar das espacializações dos fenômenos meteorológicos, mas, também por considerar a interação desses fenômenos com meio social. Por isso, torna-se importante o entendimento dos fenômenos climáticos para o cidadão, uma vez que o indivíduo passa a entender melhor o espaço onde vive a partir da compreensão da interação do clima com a dinâmica social a sua volta.

A climatologia possui um papel importante na sociedade. Compreende se o clima segundo Ayoade (2010), como um importante elemento do ambiente natural, pois atua diretamente como os processos de formação do relevo, pedologia, e desenvolvimento das paisagens terrestres, fornecendo os principais fatores que permitem a vida da humanidade que são o ar e água e todos os outros que desencadeiam a partir desses. (BARBOSA; OLIVEIRA, 2012, p.111).

Pode-se afirmar que o estudo de clima tem relação direta com o estudo de biomas, relevos, erosões, sistemas hidrográficos, plantações, hábitos culturais e etc. Por isso, torna-se necessário para o estudante entender as dinâmicas atmosféricas, para que compreendam as dinâmicas espaciais que ocorrem onde vivem, compreendam os fenômenos climáticos e seus elementos que estão diretamente ligados a diversos conteúdos da própria geografia e, por fim, consigam compreender também conteúdos de outras áreas/disciplinas.

Ao discutir o clima dentro dos centros urbanos, é preciso considerar o fenômeno climático agindo conjuntamente com elementos e fatores que podem não ser puramente naturais. Pode-se citar alguns desses elementos como frutos da ação humana, a poluição atmosférica pela queima de combustíveis fósseis por automóveis, indústrias ou liberação de gás metano, também proveniente da concentração de lixo em algumas áreas urbanas, que geram alterações no clima local. De acordo com Monteiro (2015), Sant'anna Neto (2015) e Zavattini (2015), observa-se uma nítida orientação dos estudos de clima urbano para a análise de formação de impactos, riscos e vulnerabilidades socioambientais relativas à atmosfera urbana, além de forte influência na economia e mudanças no comportamento e hábitos humanos. Partindo das informações abordadas sobre os centros urbanos, faz-se necessária uma mediação que permita aos alunos se apropriarem dos conceitos climáticos e utilizarem como ferramenta de análise e compreenderem o espaço a sua volta.

Steinke (2012) e Fortuna (2011) discutem não somente a relevância do ensino de clima, mas metodologias de ensino que permitam uma melhor mediação e entendimento do educando para com os conteúdos climáticos apresentados nos documentos.

Esse trabalho justifica a opção pelo tema abordado porque de forma mais simples, as informações envolvendo a climatologia, sejam elas características das estações do ano, chuvas ou ilhas de calor no espaço urbano e todas as relações que o clima tem com o meio socioeconômico - são temas mais habituais e estão sempre presentes no cotidiano dos alunos e retratados pelos veículos de comunicação. Apesar disso, não são percebidos numa forma mais consciente e analítica por tais sujeitos, pois eles encontram dificuldades para associar paisagem, clima e ao espaço geográfico, (TORRES; MACHADO, 2011, OLIVEIRA; CHAGAS; ALVES, 2012).

Desta forma, o objetivo deste trabalho é analisar a importância do estudo de clima para desenvolver a mediação do conhecimento geográfico em sala de aula.

ParaOnde!?, Porto Alegre, v.12 n.2, p.146-154, 2019. http://seer.ufrgs.br/paraonde Edição Especial - III Colóquio de Pesquisadores em Geografia Física Ensino de Geografia 
Compreende-se que o fenômeno climático acontece cotidianamente no espaço geográfico modificando paisagens, tornando-se importante seu entendimento.

Para o desenvolvimento da pesquisa, foi escolhida a escola Grupo Potência, localizada no município de Magé-RJ, situada na Baixada Fluminense, na Região Metropolitana do Rio de Janeiro. Esta pesquisa teve início em setembro 2017 e será finalizada em junho de 2019, em turmas cursando o primeiro ano do ensino médio.

Os dados adquiridos e apresentados aqui são parte da dissertação de mestrado, que será apresentada na Universidade do Estado do Rio de Janeiro, na Faculdade de Formação de Professores (UERJ-FFP), no primeiro semestre de 2019. Tais dados para a pesquisa da pós-graduação serão coletados a partir da aplicação de cinco instrumentos/recursos aplicados aos alunos. Contudo, para o presente trabalho será apresentado apenas dois recursos: o uso de notícias online de jornais e telejornais, envolvendo o clima, que foram mediados em sala entre os meses de maio e julho no segundo bimestre de 2018. As notícias online e de telejornais envolvendo economia, agricultura, meio ambiente, desastres naturais e problemas urbanos permitirão que os estudantes façam leituras espaciais, a partir do clima em diferentes áreas e conteúdos.

A discussão promovida neste trabalho aborda a importância do ensino de clima para a formação do indivíduo enquanto leitor de seu espaço de vivência. Também comprova que é possível ir além do livro didático e do quadro negro, para mediar e construir o conhecimento em sala de aula. A metodologia utilizada é a qualitativa, na qual o conhecimento é construído pelos agentes envolvidos no processo e envolve o uso de diferentes instrumentos didáticos para a compreensão do educando, assim como a análise de suas leituras e interpretações do espaço, a fim de ser feita a mediação para o ensino de clima e suas dinâmicas espaciais.

\section{Desenvolvimento}

A pesquisa-ação é uma metodologia bastante utilizada em pesquisas na área da educação e ensino. Essa metodologia objetiva informar a ação tomada para melhorar a prática, seja ela onde e qual for, dentro da pesquisa. Frequentemente, serão produzidos dados sobre os efeitos de uma mudança da prática, durante a implementação e mediante observação. Segundo Elliott (1997, p.15), a pesquisa-ação permite preencher as lacunas existentes entre a pesquisa educativa e a prática docente, logo, entre teoria e prática, e seus resultados expandem as capacidades de compreensão do professor e sua prática. Por isso, favorecem relevantemente as mudanças no âmbito da educação.

O pesquisador é um agente ativo caso escolha essa metodologia, ainda que leve em consideração o coletivo e se tenha a colaboração de todos os evolvidos, ainda assim seu papel é essencial. Ele escolhe o objeto e age em todo o processo, do início ao final da pesquisa, se encaixando à noção de Sachs (2003) de "profissional ativista". Não apenas se compreende a prática de modo a contribuir na pesquisa-ação, mas também se ganha um melhor entendimento dessa ação cotidiana, de modo a utilizar o contexto, 0 meio e a finalidade principal que é a compreensão para construção do ensino.

É fundamental que se reconheça essa metodologia de pesquisa como um dos inúmeros tipos de investigação-ação, sendo um termo genérico para qualquer processo que siga um ciclo que se aprimora a prática pela oscilação sistemática entre agir no

ParaOnde!?, Porto Alegre, v.12 n.2, p.146-154, 2019. http://seer.ufrgs.br/paraonde Edição Especial - III Colóquio de Pesquisadores em Geografia Física Ensino de Geografia 
campo da prática e investigar a respeito dela. Planeja-se, implementa-se, descreve-se e se avalia uma mudança para a melhora de sua prática, aprendendo mais no decorrer do processo tanto a respeito da prática, quanto da própria investigação.

O processo começa com a reflexão sobre a prática comum, a fim de identificar o que melhorar e o ciclo termina com uma reflexão sobre o que sucedeu. Torna-se importante e se tem demostrado eficaz o uso de diferentes recursos didáticos para 0 ensino de geografia, segundo STEINKE (2015) e PEREIRA, LIMA e BEZERRA (2017). Nesse sentido, instrumentos metodológicos serão utilizados em diferentes métodos: notícias online retiradas de jornais e telejornais. Esses recursos didáticos trazem os conteúdos e conceitos climáticos desde o senso comum dos educandos até definições mais científicas. Isto permitirá uma potencialização da leitura espacial do lugar vivido pelos alunos, uma vez que esses conceitos forem sendo entendidos e se tornando conhecimento.

As notícias online escolhidas dos jornais foram: "Chuva forte deixa várias ruas do Rio alagadas" (www.oglobo.globo.com - 21/02/2018), "Preço do feijão carioca sobe 115\% em um mês" (www.canalrural.com.br - 23/05/2017), "Criança morre após deslizamento de terra em Petrópolis no Rio" (www.brasil.estadao.com.br - 09/03/2018), "Brasil terá aumento de mortes por ondas de calor, afirma estudo" (www.estadao.com.br 02/08/2018). Também foi utilizado partes do telejornal "Jornal Hoje" apresentado pela Rede Globo RJ nos dias 07 e 10 de agosto de 2018 às 13h30hs. Nessas edições do Jornal Hoje, as reportagens trouxeram vários acontecimentos envolvendo o clima em diferentes latitudes do planeta. Mostraram as medidas de políticas públicas que Nova York (EUA) toma para enfrentar o aumento do calor no centro da cidade; mostraram os incêndios enfrentados pela Califórnia, mostraram as tempestades de granizo que isolam pessoas na República Popular da China, assim como em Belo Horizonte, no território brasileiro, além das chuvas congeladas no sul do Brasil.

Propostas didáticas foram apresentadas aos alunos e, a partir da mediação docente e interação discente, ocorreu a construção do conhecimento geográfico a partir do ensino de clima. Onde as notícias de jornais e telejornais constituíram os instrumentos utilizados em sala de aula. Essas propostas foram utilizadas como ferramentas na tentativa de aproximar os conteúdos das aulas de geografia com o cotidiano dos educandos, ajudando-os a identificar como clima interfere e age no meio onde vivem.

Um dos recursos utilizados foram os fatos noticiados nos jornais envolvendo o clima. Desta forma, o aluno pode identificar a ação das dinâmicas da atmosfera recorrentes no espaço vivido. Os alunos conseguiram observar e apontar essas ações da natureza sobre seus próprios espaços, neste caso, no município de Magé, além de notar as interações, ainda que nem sempre positiva dessa da atmosfera com o meio social. Usar notícias atuais que envolvem os conteúdos da geografia para análise em sala é um importante instrumento de mediação para a geografia (COELHO; STEINKE, 2013).

O livro didático, geralmente, não contextualiza ou relaciona as áreas de ensino, fortalecendo a dicotômica questão da fragmentação da geografia entre física e humana. Quando se apresenta aos alunos informações que são comuns no seu cotidiano, permitindo que eles possam fazer uma análise mais integrada e ampla, utilizando outras ferramentas de análise como as notícias de jornais e telejornais e não somente o livro didático; abre-se a possibilidade para o educando perceber na prática as relações entre meio físico e social (PEREIRA; LIMA; SILVA, 2017).

ParaOnde!?, Porto Alegre, v.12 n.2, p.146-154, 2019. http://seer.ufrgs.br/paraonde Edição Especial - III Colóquio de Pesquisadores em Geografia Física Ensino de Geografia 
Diante da leitura e da compreensão das notícias, os alunos conseguiram entender que a climatologia também pode ser analisada e compreendida através do ensino que envolva áreas que não são puramente físicas. Foi possível ajudá-los a compreender a importância desse ensino para a compreensão das várias dinâmicas e fenômenos espaciais que ocorrem a sua volta. O clima está diretamente relacionado a sua cultura, hábitos e atividades, sejam elas econômicas ou de lazer. Dessa forma, o ensino de clima assume o papel como importante ferramenta para leitura espacial.

De acordo com a consultoria Safras \& Mercado, os preços passaram de $\mathrm{R} \$ 157,50$ para $\mathrm{R} \$ 340$ neste mês. Entre os principais motivos para essa expressiva alta (...) estão as preocupações com possíveis prejuízos, causados pelo clima (...). O real fator para está elevação foi a preocupação com o excesso de chuva na região sul do Brasil (canalrural.com.br. 23/05/2017).

Por meio da leitura das notícias, os estudantes precisaram trabalhar a interpretação e leitura do espaço, utilizando o entendimento das dinâmicas climáticas, para uma compreensão significativa e ampla dos fatos que foram relatados pelos jornais. Isso porque, geralmente, o livro didático traz conteúdos separados como se devessem ser entendidos desconectados a outras áreas dentro da própria ciência geográfica. Tal fato dificulta uma aprendizagem integrada e qualificada. Para que o ensino de clima seja um instrumento importante para a formação do estudante, é preciso que esse ensino seja contextualizado e visto de forma integrada a outros conteúdos e processos.

Esses meios permitem uma leitura espacial em diferentes áreas e conteúdos da geografia, propiciando uma leitura mais integrada do espaço geográfico. Com essas informações da atualidade, os estudantes conseguiram perceber como os fenômenos climáticos agem de formas diversas, distintas e simultâneas em diferentes áreas do globo terrestre. Tal fato causou curiosidade e vários questionamentos nos alunos, porque, enquanto uma área se preocupa com o calor e queimadas naturais em seu território, outras áreas enfrentam períodos de baixas temperaturas, chegando a ter sua flora congelada.

Um ponto importante foi levar os alunos a compreender - a partir das reportagens apresentadas - que a interação do clima com o meio social - principalmente, com a vida urbana e rural - é influenciada e inclusive dependente de um tipo de clima. Outro ponto relevante é relacionar os fatos vistos nas notícias com os fenômenos locais, investigando se são possíveis no município de Magé área da pesquisa ou não, para que o discente se aproprie do conhecimento e saiba identificá-lo na sua região. É preciso despertar a curiosidade dos alunos, pois esta prática pedagógica torna o processo de ensino mais dinâmico, já que eles precisam encontrar as respostas para seus questionamentos.

Logo após a aplicação da aula, foi realizada uma discussão com os alunos envolvendo o tema da climatologia e seus conteúdos, sendo esse o momento para esclarecer dúvidas e orientar possíveis equívocos através das leituras realizadas. Esse procedimento que envolve a leitura das notícias de problemas sociais, a partir das variações de tempo meteorológico, fez-se relevante para essa pesquisa, pois identificouse de qual forma a compreensão dos alunos sobre o clima se construiu, o que eles sabem, o que eles não sabem, o que percebem do clima no lugar onde vivem, além de suas interações com outras áreas e como ocorre. Sendo assim, a constatação sobre o desenvolvimento do raciocínio geoclimático do alunado evidenciou que uma aula mais didaticamente reflexiva facilita o processo de aprendizagem.

ParaOnde!?, Porto Alegre, v.12 n.2, p.146-154, 2019. http://seer.ufrgs.br/paraonde Edição Especial - III Colóquio de Pesquisadores em Geografia Física Ensino de Geografia 
Todos esses fatos foram noticiados em jornais e telejornais traziam consigo as variações meteorológicas e dinâmicas atmosféricas como responsáveis pelos fatos ocorridos. A leitura e compreensão dessas notícias foram relevantes para 0 aluno perceber que o entendimento de clima não se baseia somente em diferença entre elementos e fatores, mas sim diretamente relacionado a problemas socioeconômicos.

\section{Considerações finais}

Considerar o saber prévio do corpo discente, assim como trabalhar sua interpretação das notícias sobre conteúdos climáticos tornaram-se métodos eficazes para o processo de conhecimento e leitura espacial entre professor e alunos.

Está sendo comprovado ao longo da pesquisa que os discentes carregam consigo informações e saberes que foram construídos por meio de suas vivências e observações diárias sobre os lugares onde vivem. E assim, podem identificar as representações acerca de diversos aspectos que vão criando e reproduzindo por meio de suas interações com o clima e a sociedade a sua volta. É papel do professor analisar essas representações que são construídas por meio do senso comum e que precisam ser ratificadas, retificadas e/ou ressignificadas, por intermédio do conhecimento científico, no caso escolarizado. Portanto, não se pode descartar imediatamente esse tipo de saber que os alunos trazem consigo para a escola.

Esta pesquisa traz importantes contribuições para o ensino de geografia a partir do clima. Desta maneira, pode contribuir também na formação discente ao permitir uma leitura espacial que relaciona a natureza e sociedade sem separá-las. Os resultados já obtidos são satisfatórios, juntamente com o interesse do aluno pelas aulas, já que é parte ativa dela.

Logo, entende-se a necessidade de estimular o estudante a se posicionar como cidadão consciente e que esteja apto para leitura de seu espaço e de todas as possibilidades e limitações, além de aprender de forma científica a analisar seu cotidiano, unindo suas experiências com o que aprendeu em sala. Este fato é uma prova de que a escola é um espaço de aprendizado que permite o uso de instrumentos de análise e percepção úteis para a vida e, por isso, não deve ser visto como um espaço de aprendizado inútil, mas que ofereça um saber útil para além de seus muros.

$\mathrm{Na}$ escola, a disciplina de geografia deve ser tratada como uma disciplina que a cada dia se estabelece como uma ciência relevante na formação do cidadão. Assim, diante das enormes responsabilidades que essa matéria possui, enfatiza-se a importância de trabalhar de forma significativa e coerente com os recursos que estão presentes na vida dos alunos.

\section{Referências}

COELHO, Lucas Lima; ALVES, G. A. ; STEINKE, Ercilia Torres . O jornal impresso como ferramenta de ensino na Climatologia Escolar do Ensino Fundamental. In: Encontro Nacional de prática de Ensino de Geografia, 2013, João Pessoa. Anais do Encontro Nacional de prática de Ensino de Geografia. Anais...João Pessoa: UFPB, 2013. p. 1-7.

ParaOnde!?, Porto Alegre, v.12 n.2, p.146-154, 2019. http://seer.ufrgs.br/paraonde Edição Especial - III Colóquio de Pesquisadores em Geografia Física Ensino de Geografia 
ELLIOTT, Jhon. La investigación-acción en educación.3a․ ed. Madrid: Morata, 1997.

FORTUNA, Denizart da Silva. As Abordagens da Climatologia nas Aulas de Geografia do Ensino Fundamental (segundo segmento): primeiras impressões. In: IV Seminário de Pesquisadores do Instituto de Ciências da Sociedade e Desenvolvimento Regional (ESR). Universidade Federal Fluminense (UFF). Campos dos Goytacazes (RJ). Anais...2011, pp. 1-10.

MENDONÇA, Francisco; DANNI-OLIVEIRA, Inês Moresco. Climatologia: noções básicas e climas do Brasil. São Paulo: Oficina de textos, 2007.

MONTEIRO, Carlos Augusto de Figueiredo (org). A climatologia Geográfica no Brasil e a proposta de um novo paradigma In: A construção da climatologia geográfica no Brasil. In: Campinas, SP: Editora Alínea, 2015, p. 61 - 126.

OLIVEIRA, Divino José Lemes de; CHAGAS, Frank Luiz Rosa; ALVES, Washington Silva. Os desafios de ensinar a climatologia nas escolas. In: 2 Congresso de educação UEG/UNU, Iporá, Goiás. Anais..., 2012. p. 47 - 51.

PEREIRA, Taísa das Dores. LIMA, Maria do Socorro Bezerra. Silva, Maria Gertrudes Alvarez Justi. Relato de experiências desenvolvidas com estudantes da NEJA no ensino de climatologia em Baixa Grande - Campo dos Goytacazes/RJ. Revista do Departamento de Geografia, USP. São Paulo. Volume especial - XVII SBGFA - / I CNGF (2017). P. 01-09. Junho, 2017.

SACHS, Judyth. The activist teaching profession. Buckingham: Open University Press, 2003.

SANT'ANNA NETO, João Lima. As matrizes da construção da climatologia geográfica brasileira. In: MONTEIRO, Carlos Augusto de Figueiredo (org). A construção da climatologia geográfica no Brasil Campinas, SP: Editora Alínea. 2015, p. 07-53.

STEINKE, Ercília Torres. Climatologia fácil. São Paulo: Oficina de Textos, 2012.

STEINKE, Ercília Torres. Conteúdos de Climatologia na Geografia Escolar. In: RABELO, Kamila Santos de Paula; BUENO, Miriam Aparecida. (Org.). Currículo, políticas públicas e ensino de Geografia. 1ed. Goiânia: PUC- Goiás, 2016, p. 231-242.

STEINKE, Ercília Torres; FIALHO, Edson Soares. Projeto Coletivo sobre avaliação dos conteúdos de climatologia nos livros didáticos de Geografia dos $5^{\circ}$ e $6^{\circ}$ anos do ensino fundamental. Revista Brasileira de Climatologia, v. 20, p. 71-97, 2017.

TORRES, Fillipe Tamiozzo Pereira; MACHADO, Pedro José de Oliveira. Introdução a climatologia. São Paulo: Cengage Learning, 2011.

ZAVATTINI, João Afonso. Dinâmica atmosférica e análise rítmica: a contribuição do brasileiro Carlos Augusto de Figueiredo Monteiro à França de Pédelaborde e à Itália de Pinna. In: MONTEIRO, Carlos Augusto de Figueiredo (org). A construção da

ParaOnde!?, Porto Alegre, v.12 n.2, p.146-154, 2019. http://seer.ufrgs.br/paraonde Edição Especial - III Colóquio de Pesquisadores em Geografia Física Ensino de Geografia 
climatologia geográfica no Brasil Campinas, SP: Editora Alínea. 2015, p. 167-187.

\section{Site utilizados}

O preço do feijão-carioca sobe $115 \%$ em um mês.

Disponível em <www.canalrural.com.br/noticias/mercado-e-cia/preco-feijao-carioca-sobe115-mes-67460 >. Acesso em: 01de abr. 2018.

Chuvas fortes deixam várias ruas do Rio alagadas.

Disponível em <oglobo.globo.com/rio/chuva-forte-deixa-varias-ruas-do-rio-alagadas22418569>. Acesso em: 01 de abr. 2018.

Criança morre após deslizamento de terra em Petrópolis, no Rio.

Disponível em <www.brasil.estadao.com.br/noticias/rio-de-janeiro,crianca-morre-aposdeslizamento-de-terra-em-petropolis-no-rio,70002220193>. Acesso em: 01 de abr. 2018.

Brasil terá aumento de mortes por ondas de calor, afirma estudo.

Disponível em: www.sustentabilidade.estadao.com.br/noticias/geral,brasil-tera-aumentode-mortes-por-ondas-de-calor-afirma-estudo,70002424589?from=whatsapp. Acesso em 02 de ago. 2018. 